\title{
Ecosystem Restoration: A Public Health Intervention
}

\author{
Martin F. Breed®,${ }^{1,2}$ Adam T. Cross, ${ }^{3}$ Kiri Wallace, ${ }^{4}$ Keith Bradby,${ }^{5}$ Emily Flies, ${ }^{6}$ \\ Neva Goodwin, ${ }^{7,8}$ Menna Jones, ${ }^{6}$ Laura Orlando, ${ }^{7,9}$ Chris Skelly, ${ }^{2,10}$ Philip Weinstein, ${ }^{2,11}$ \\ and James Aronson ${ }^{7,12}$ \\ ${ }^{1}$ College of Science and Engineering, Flinders University, Bedford Park, Adelaide, SA 5042, Australia \\ ${ }^{2}$ Healthy Urban Microbiome Initiative (HUMI), London, UK \\ ${ }^{3}$ ARC Centre for Mine Site Restoration, School of Molecular and Life Science, Curtin University, GPO Box U1987, Bentley, Perth, WA 6102, Australia \\ ${ }^{4}$ People, Cities, and Nature, University of Waikato, Hamilton, New Zealand \\ ${ }^{5}$ Gondwana Link, PO Box 5276, Albany 6332, Australia \\ ${ }^{6}$ School of Natural Sciences, University of Tasmania, Hobart, Australia \\ ${ }^{7}$ EcoHealth Network (EHN), Albany, Australia \\ ${ }^{8}$ Economics in Context Initiative, Boston University, Boston, MA \\ ${ }^{9}$ School of Public Health, Boston University, Boston, MA \\ ${ }^{10}$ Public Health Dorset, Dorchester, UK \\ ${ }^{11}$ School of Public Health, University of Adelaide, Adelaide, Australia \\ ${ }^{12}$ Center for Conservation and Sustainable Development, Missouri Botanical Garden, 4344 Shaw Blvd, St Louis, MO 63110
}

We are seemingly locked into a downward spiral of ecological degradation, biodiversity loss, and a climate emergency. Ecological restoration aims to improve the ecological trajectory of degraded ecosystems. Ecosystem declines threaten human health (Romanelli et al. 2015, Whitmee et al. 2015). Dramatic changes in human behavior and government policy are essential, but will only occur through a profound paradigm shift explicitly linking human and ecological health. We outline the case for ecological restoration as a 'public health intervention', and provide an action plan that enables the required paradigm shift.

Health systems, world-wide, are struggling to cope with the burgeoning global burden of disease. There is a growing awareness of the environmental determinants or co-determinants of many diseases (Bhatnagar 2017, Bur-

Martin F. Breed and Adam T. Cross have contributed equally.

Published online: June 23, 2020

Correspondence to: Martin F. Breed, e-mail: martin.breed@flinders.edu.au bank et al. 2017, Prüss-Ustün et al. 2017), including allergies, immune dysfunction, infectious diseases and emerging zoonoses, and mental health disorders (Romanelli et al. 2015, Whitmee et al. 2015).

Recent examples of the synergistic consequences of climate change and ecological degradation are raising the global public consciousness. The cumulative impacts of prolonged drought, catastrophic bushfires and devastating extreme weather events have shaken Australians-and perhaps the world-over the last year. Health consequences of both drought and bushfire are well understood (Laugharne et al. 2011; Edwards et al. 2015). This year, the global spread of SARS-CoV-2, and the resulting COVID-19 pandemic, is a poignant example of how the degradation of ecosystems can contribute to the emergence of novel diseases (Cyranoski 2020).

These events cost livelihoods, are deleterious to human health, and strain health systems. Rising public health costs of the global burden of disease must incentivize society to push toward a restorative culture, and away from a culture of ecological degradation. The required paradigm shift can 
be supported by recognition that ecological degradation is driving many public health problems, and we cannot solve these public health problems without tackling ecological degradation.

The United Nations (UN) Decade on Ecosystem Restoration (https://www.decadeonrestoration.org/) and the Land Degradation Neutrality programme of the UN Convention on Combatting Desertification (https://www. unccd.int/actions/achieving-land-degradation-neutrality) encourage signatory nations to recognize the central importance of ecological restoration. There is growing understanding of the causal links between human health and ecological health, including the role of soil health and biodiversity both above and below ground (Liddicoat et al. 2020). However, while the links between environmental quality and human health are becoming better understood, the potential of ecosystem restoration as a public health intervention remains inadequately explored.

Ecological restoration improves ecological health through the reversal of ecosystem degradation, the repair of damaged ecosystems, and the reconnection of society with nature. While there have been attempts to understand and conceptualize the nexus between ecological restoration and human health, a unifying framework and resolution of the mechanisms is yet to be defined.

Two principal knowledge gaps currently limit our ability to fully realize the benefits of linking ecological restoration with public health:

1. Quantification of individual health benefit, resulting from directly participating in restoration activities (e.g., the achievement of restoring an area can reduce the anxiety and depression common among the environmentally aware); and,

2. Population health benefits resulting from the outcomes of ecological restoration (e.g., restored ecosystems providing cleaner downstream water, reducing a number of disease risks).

Although evidence is building to link ecological restoration with human health, the specific processes and mechanisms by which these health benefits might be conferred remain unclear. To unravel the links and firmly establish empirical bases for the ecological restoration-human health nexus, we propose a five-point action plan:

1. Collaborations and conversations Transdisciplinary associations of scientists, health professionals, practitioners and policymakers are required. Establishing united col- laborations will elucidate and realize the potential of ecological and human health links. Jointly achieving health and restoration goals will yield economic benefit through cost sharing.

2. Education and learning Restoration ecologists and health professionals must engage in transdisciplinary learning and capitalize on already well-established links. This will improve the shared understanding, enabling enhanced partnerships that are more effective.

3. Defining the causal links The transdisciplinary associations established in step 1 should undertake or provide opportunities for research to determine the causal links between ecosystem restoration and health outcomes. This research would clarify the importance of the ecosystem-human health nexus, and provide the empirical evidence required to know what restoration actions would most effectively improve health outcomes. A starting place for this research could leverage existing links between the health sector and environmental activities such as 'green prescriptions' (Robinson and Breed 2019).

4. Monitoring restoration and health outcomes After the causal links have been defined, methodologies that enable effective, cost-efficient monitoring and evaluation of the public health benefits from ecosystem restoration are required. These approaches could become standardized restoration monitoring and evaluation methodologies.

5. Community ownership and stewardship Community ownership through involvement with, and actual demonstration of, the cross-benefits of linking restoration with health is required. It is only with this ownership that policymakers and funders are likely to support aspirational initiatives, helping to drive the required paradigm shift. There is also a need to adequately recognize and value the importance and role of traditional ecological knowledge as part of community ownership and engagement.

Examples already exist of transdisciplinary collaborations that aim to bring together ecological restoration and human health sectors. Two such examples are the EcoHealth Network (EHN, www.ecohealthglobal.org) and the Healthy Urban Microbiome Initiative (HUMI, www.humig lobal.org/), which are interlinked global action initiatives working together at the interfaces of ecological restoration and human health. The EHN was established in 2019 and is developing an international network across a diversity of 
stakeholders (e.g., restoration practitioners and scientists, landscape designers, farmers, medical professionals) that are involved in restorative activities. HUMI was established in 2016, and is a UN-backed initiative that seeks to restore the immune-restorative power of biodiverse green spaces in cities to maximize human health gains.

The world faces extraordinary environmental and health challenges. Half the world's seven billion people currently live in cities, and this number is predicted to increase to $70 \%$ by 2030 (Rydin et al. 2012). Urbanization is driving ecosystem degradation and biodiversity loss that is, in turn, causing increasing levels of chronic disease, resulting in dramatic health budget increases. The global demographic shift and increasing health crisis is defined by humanity's loss of connection with the natural world. It is all the more tragic for having mostly ignored Indigenous voices on our connection with nature. We now mostly live in biologically impoverished cities, and our demand for environmental resources has led to this global environmental crisis. Ecological restoration is a clearly identifiable pathway to tackle some of our most critical challenges, as it becomes increasingly clear that the human and ecological health crises are intimately interwoven. Improved understanding of the links between ecological restoration and human health will catalyze the required investment into this most fundamental of public health interventions, which will likely result in environmental and health gains that pay generational dividends.

\section{Compliance with Ethical Standards}

CONFLICT OF INTEREST The authors declare no competing interests.

\section{REFERENCES}

Bhatnagar A (2017) Environmental determinants of cardiovascular disease. Circulation Research 121:162-180. https://doi.org/ 10.1161/CIRCRESAHA.117.306458
Burbank AJ, Sood AK, Kesic MJ, Peden DB, Hernandez ML (2017) Environmental determinants of allergy and asthma in early life. Journal of Allergy and Clinical Immunology 140:1-12. https://doi.org/10.1016/j.jaci.2017.05.010

Cyranoski D (2020) Mystery deepens over animal source of coronavirus. Nature . https://doi.org/10.1038/d41586-02000548-w

Edwards B, Gray M, Hunter B (2015) The impact of drought on mental health in rural and regional Australia. Social Indicators Research 121:177-194. https://doi.org/10.1007/s11205-0140638-2

Laugharne J, Van de Watt G, Janca A (2011) After the fire: the mental health consequences of fire disasters. Current opinion in psychiatry 24:72-77. https://doi.org/10.1097/YCO.0b013e32833f5e4e

Liddicoat C, Sydnor H, Cando-Dumancela C, Dresken R, Liu J, Gellie N, Mills J, Young J, Weyrich L, Hutchinson M, Breed MF (2020) Naturally-diverse airborne environmental microbial exposures modulate the gut microbiome and may provide anxiolytic benefits in mice. Science of the Total Environment . https://doi.org/10.1016/j.scitotenv.2019.134684

Prüss-Ustün A, Wolf J, Corvalán C, Neville T, Bos R, Neira M (2017) Diseases due to unhealthy environments: an updated estimate of the global burden of disease attributable to environmental determinants of health. Journal of Public Health 39:464-475. https://doi.org/10.1093/pubmed/fdw085

Robinson J, Breed MF (2019) Green prescriptions and their cobenefits: integrative strategies for public and environmental health. Challenges . https://doi.org/10.3390/challe10010009

Romanelli C, Cooper D, Campbell-Lendrum D, Maiero M, Karesh WB, Hunter D, Golden C (2015) Connecting global priorities: biodiversity and human health: a state of knowledge review. World Health Organistion/Secretariat of the UN Convention on Biological . https://doi.org/10.13140/RG.2.1.3679.6565

Rydin Y, Bleahu A, Davies M, Dávila JD, Friel S, De Grandis G, Groce N, Hallal PC, Hamilton I, Howden-Chapman P (2012) Shaping cities for health: complexity and the planning of urban environments in the 21st century. Lancet 379:2079. https:// doi.org/10.1016/S0140-6736(12)60435-8

Whitmee S, Haines A, Beyrer C, Boltz F, Capon AG, de Souza Dias BF, Ezeh A, Frumkin H, Gong P, Head P (2015) Safeguarding human health in the Anthropocene epoch: report of The Rockefeller Foundation-Lancet Commission on planetary health. The Lancet 386:1973-2028. https://doi.org/10.1016/ S0140-6736(15)60901-1 